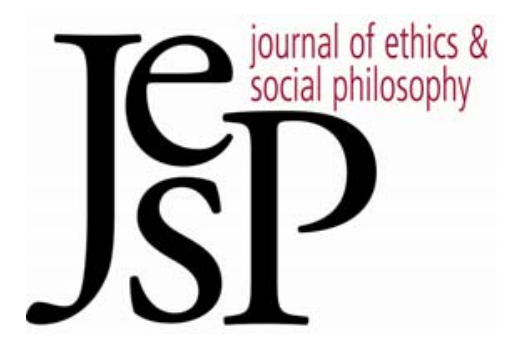

\title{
WHAT Is WRONG WiTH KAMM AND SCANLON'S ARGUMENTS AGAINST TAUREK
}

BY TYLER DOGgETT 


\section{What Is Wrong With Kamm and Scanlon's Arguments Against Taurek ${ }^{1}$ Tyler Doggett}

$\mathrm{I}$

F YOU DO NOTHING, ALAN, BOB and Christine will die. Death will cost each the same: each will lose thirty-odd years of a good life. Their deaths will cost others the same: each will be missed by friends and family. Some medicine is nearby and with it you can save some but not all: Alan needs all the medicine; Bob and Christine need only half each. It would be easy for you to distribute the medicine and you have no need of it yourself. You have no special ties to any of them: none is your relative, charge, friend, etc. What should you do? Generally, when you have a choice between saving a larger group, the many, or a smaller group, the few, where there is no overlap in members, where the stakes are the same for everyone, where saving would cost you next to nothing, and where you have no special obligations, what should you do?

According to

Must Save Many - you are required to save the many.

This view is defended quite often. Its ever being defended is surprising since it seems so obvious. But consider

Can Save Few - you are required to save someone but permitted to save the many or the few.

This view can be embellished by adding that, though you are permitted to save the many or the few, you are required to decide who to save by flipping a coin, or adding that you are required to decide who to save by holding a weighted lottery or... These embellishments of Can Save Few, like Can Save Few itself - just focus on Can Save Few - have been provocatively defended, and those defenses have precipitated support for Must Save Many.2 Such

1 Thanks to Selim Berker, Ben Bradley, Terence Cuneo, Caspar Hare, James John, Arthur Kuflik, Don Loeb, Derk Pereboom, Philip Stratton-Lake, Judith Jarvis Thomson and two anonymous referees for helpful comments.

2 More precisely, Can Save Few posits that you are morally required to save a group, you can save either group, and you are required to save all the members of whichever group you save. Saving only Bob in the Alan, Bob and Christine case is impermissible, if Can Save Few is true.

John Taurek defends Can Save Few and adds that he would flip a coin to figure out who to save. Nothing hangs on this and it is controversial, but I think Taurek's view is not that there is a moral requirement to flip a coin. See his (1977): 303, 306. G.E.M. Anscombe also holds Can Save Few and does not see the need to flip a coin. See her (1967). Veronique Munoz-Dardé (2005) agrees for at least some cases like the one this paper started with. Jens Timmerman holds Can Save Few and adds that you are required to figure out who to save by holding a weighted lottery. See Timmerman (2004). 
support has tried to explain why Can Save Few is false and why Must Save Many is true. For even if Must Save Many really is obvious, why it is true is not obvious and neither is it obvious why Can Save Few is false.

For more than twenty years, Frances Kamm and T.M. Scanlon have refined arguments explaining why Can Save Few is false and why Must Save Many is true. These arguments are important because of their influence ${ }^{3}$ and because they are among the very few nonconsequentialist explanations of Must Save Many. But the arguments do not work. The argument against Can Save Few is unsound, and seeing why it is unsound enhances Can Save Few's appeal. The argument in favor of Must Save Many is open to three interpretations, but each is unsound, and what is wrong with the best interpretation further enhances Can Save Few's appeal.

\section{Against Can Save Few}

Kamm and Scanlon argue against

Can Save Few - you are required to save someone but permitted to save the many or the few

as follows. First, if Can Save Few is true, only some of those whose lives are at stake make a difference to what you are permitted to do in such cases as the one at the start of this paper. Second, a view according to which only some whose lives are at stake make a difference to what is permitted is untrue. It is untrue because such a view would be unfair to those whose lives make no difference. The true view of what to do in such cases as the one at the start of this paper must be fair. Hence, Can Save Few is not true. ${ }^{4}$

Taurek actually seems open to the view that you are permitted to save no one but assumes that view away. See Taurek (1977): 293, fn. 1. I make the same assumption.

${ }_{3}^{3}$ Bradley (2009), Brock (1998), Broome (1998), Hsieh, Strudler and Wasserman (2006), Kumar (2001), Lübbe (2008), Munoz-Dardé (2005), Norcross (2002), Otsuka (2000), Otsuka (2006), Parfit (2003), Raz (2003), Suikkanen (2004), Timmerman (2004), and Wasserman and Strudler (2003), among many others, discuss Kamm and Scanlon's arguments.

4 The argument is in Kamm (1984): 180-182, Kamm (1993): 99-122, Kamm (1998): 940-941, Kamm (2000): 33 and Kamm (2005): 53. Scanlon states it like this,

[Can Save Few] would permit someone, faced with the choice between saving one stranger from...death and saving two other strangers from the same fate, to save only the one. In such a case, either member of the larger group might complain that this principle did not take account of the value of saving his life, since it permits the agent to decide what to do in the very same way that it would have permitted had he not been present at all, and there was only one person in each group. The fate of the single person is obviously being given positive weight, he might argue, since if that person were not threatened then the agent would have been required to save the two. And the fact that there is one other person who can be saved if and only if the first person is not saved is being given positive weight to balance the value of saving the one. The presence of the additional person, howev- 
About the first premise: why doesn't everyone make a difference, if Can Save Few is true? What, exactly, does not making a difference come to? These questions can be answered with examples.

In the A case, Alan alone needs medicine and you can give it to him easily. In that case, you are morally required to save Alan. Hence, Alan makes a difference to what you are permitted to do: his being on the scene is what requires you to save someone. In the $\mathrm{AB}$ case, Alan and Bob need medicine and you can easily save one but only one. In that case, you have to save someone, but that someone can be Alan or Bob. Put slightly misleadingly, you have to save one group, and you can save either group. This differs from what you are permitted to do in the A case, and the difference is due to Bob's presence. Hence, he makes a difference to what you are permitted to do. In the $\mathrm{ABC}$ case, the case at the start of this paper, Alan, Bob and Christine need medicine. You can easily save Alan, or both Bob and Christine, but not everyone. If Can Save Few is true, you have to save one group, and you can save either group. That is just as things are in the $\mathrm{AB}$ case, so Christine, unlike Alan and Bob, appears to make no difference to what you are permitted to do. That is unfair to Christine. The true view of what to do in the ABC case must be fair. So Can Save Few is false. So goes Kamm and Scanlon's argument against Can Save Few.

I think Kamm and Scanlon are mistaken about all this. Christine does make a difference to what is permitted, if Can Save Few is true. Not only that, but she, being morally like Alan and Bob, also makes a like difference to what is permitted. This addition is important. A view of the ABC case according to which you are permitted to save Alan, permitted to save Bob, required to save one of them, and required merely to give Christine a cookie, is awful even though Christine, according to the absurd view, makes a difference to what is permitted - you have to give her a cookie. But the view is unfair since Christine is like Alan and Bob in what she needs and what it takes to save her. A necessary condition for a view being fair, according to Kamm and Scanlon, is that like persons make like differences to what is permitted. Unlike the absurd view, Can Save Few meets this condition. If it is true, Alan, Bob and Christine do make like differences to what is permitted, viz., you are permitted to save each person and, if you save someone in his or

er, makes no difference to what the agent is required to do or to how she is required to go about deciding what to do. This is unacceptable, the person might argue, since his life should be given the same moral significance as anyone else's in this situation.... (Scanlon (1999): 232)

Kamm and Scanlon argue that the principle covering what you ought to do in such cases as the one at the start of this paper must be fair. They then argue that it is necessary - and, I believe, sufficient - for a principle's being fair that each like person make a like difference to what is permitted. Kamm and Scanlon think that Can Save Few fails to meet these necessary conditions and, hence, is not true. Kamm and Scanlon's view is not, for reasons to be explained, that any view according to which each makes a difference to what is permitted is true. Neither is it that that any fair principle is true. See footnote five for more. 
her group, you are required to save everyone else in the group, too. Hence, who you are allowed to save varies from case to case: you can save Alan in the A case, Alan or Bob in the AB case, and Alan or Bob and Christine in the $\mathrm{ABC}$ case.

Of course, if Can Save Few is true, you can save the many or the few no matter how many people are in the many and the few in cases such as the $\mathrm{ABC}$ case. That consequence of Can Save Few does not show that some make no difference to what is permitted, though. Compare the following: if Must Save Many is true, you are required to save the many no matter how many people are in the many and the few. Consider the ABCD case, just like the $\mathrm{ABC}$ case except that you can save Diane along with Bob and Christine. If Must Save Many is true, you are required to save the many. That is just as things are in the ABC case, but that hardly shows that, if Must Save Many is true, Diane makes no difference to what is permitted. In the ABCD case, unlike the $\mathrm{ABC}$ case, you are required to save Diane, if Must Save Many is true - so she makes at least that much difference to what you can do. ${ }^{5} \mathrm{~A}$ defender of Can Save Few can make an equally plausible claim: if Can Save Few is true, then, in the $\mathrm{ABC}$ case, unlike the $\mathrm{AB}$ case, you are permitted to save Christine and required to save her if you save Bob - so she makes at least that much difference to what you can do.

True, if we think of Alan, Bob and Christine as stranded on islands, and add Diane to Bob and Christine's island, then, if Must Save Many is true, Diane makes no difference to which island you are allowed to go to. Must Save Many and Can Save Few are alike in that way. But, if either is true, Diane does make a difference to who you have to put into the rescue boat. In this way, she differs from sand on the beach: that sand makes no difference to which island you go to or who you put in the boat. This is the crucial point about Can Save Few. If it is right, who you are allowed to save varies from case to case and each person makes the same difference to who you can save: you can save them and have to save everyone else you can save along with them. Kamm and Scanlon are, of course, right that, if Can Save Few is true, the form of your obligation in the $\mathrm{AB}$ case, the $\mathrm{ABC}$ case and the $\mathrm{ABCD}$ case remains the same: you can save one group or the other, and you have to save one. But which people you are required to save varies with the case. An exactly similar point applies to their own view. If Must Save Many is true, the form of your obligation in the $\mathrm{ABC}$ case and the $\mathrm{ABCD}$ case remains the same: you must save the many. But which people you are required to save varies with the case.

${ }^{5}$ Another example makes the same point: Kamm believes that, in the AB case, you have to give Alan and Bob an equal, maximal chance at survival - you have to, say, flip a coin. Christine and Ed come onto the scene. Save Alan and you can save Ed, too, but only Ed. Save Bob and you can save Christine, too, but only Christine. Again, you have to flip a coin, Kamm would think. But Kamm would not think that shows Christine and Ed make no difference to what is permitted, even though you have to flip a coin in this case, just as, Kamm thinks, you do in the AB case. Cf. Norcross (2002): 304-305 and Otsuka (2006): 113-114. 
A final attempt at sustaining Kamm and Scanlon's objection: if Must Save Many is true, Diane makes this difference in the ABCD case - if Christine were absent, Diane's presence would ensure that you are still required to save the many. But Can Save Few lets Christine make a similar difference: if Bob were absent, Christine's presence would ensure that you are still permitted to save either group. You would not have to save Alan.

So Can Save Few is not open to Kamm and Scanlon's objection. Can Save Few has each like person make a like difference to what is permitted. So, by Kamm and Scanlon's own lights, it is fair. But not every fair view is true. It might be that the "makes no difference" talk means to make the point that if Can Save Few is true, then Christine makes the wrong difference to what is permitted. Kamm and Scanlon think that when Christine joins Alan and Bob, you go from a situation - the AB case - in which you are permitted to save either group to one - the $\mathrm{ABC}$ case - in which you are required to save the many. That is not the difference Christine makes to permissibility if Can Save Few is true. ${ }^{6}$ But to insist that Christine's presence alongside Bob makes for a requirement to save the many is not to argue against Can Save Few, it is just to endorse Must Save Many. Why endorse it?

${ }^{6}$ Compare with Kamm and Scanlon on Timmerman's view that, in the ABC case, you are required to hold a weighted lottery and save whoever wins. If Timmerman is right, each like person makes a like difference to what is permitted: each makes the same impact on lottery odds. So Kamm and Scanlon do not think the view is flawed in the way they think Can Save Few is. They acknowledge that the view is fair. (This is the best evidence that they believe the view that like persons making like differences to what is permitted suffices for the fairness of a principle.) What is wrong with the weighted lottery view, they think, is that it has people making the wrong difference to what is permitted. Scanlon writes,

...In a case in which we must choose between saving one person and saving two, a principle that did not recognize the presence of the second person on the latter side as making a moral difference counting in favor of saving that group, could reasonably be rejected. The case for using a weighted lottery acknowledges this, since the reason for weighting the lottery rather than using one that grants everyone an equal chance of being saved is that this reflects the positive value of saving each person: everyone's presence makes a difference to the procedure that is followed, counting in favor of the action that would lead to his or her being saved. Why, then, doesn't this settle the matter? If there is a strong reason...to save this person, then deciding on this ground to save the two-person group is not unfair to the person who is not saved, since the importance of saving him or her has been fully taken into account. There is no reason at this point, to reshuffle the moral deck by holding a weighted lottery, or an unweighted one. (Ibid.: 234; cf. Kamm (1993): 136-139)

Scanlon, like Kamm, thinks you should not hold a weighted lottery. You should save the many straightaway. This is because, though the weighted lottery view does allow like persons to make like differences, it has them make the wrong difference: the fact that Christine is dying and you can easily save her supports a reason to save her and not a reason to have Christine's fate decided in a certain way.

If my interpretation of the passage is correct, Wasserman and Strudler are wrong to say that Scanlon has no objection to the weighted lottery ((2003): 84). 


\section{For Must Save Many}

Kamm writes,

[1] $\mathrm{n}$ conflict case involving unequal numbers each of whose life is at stake,...each person on one side should have her interests balanced against those of one person on the opposing side; those whose interests are not balanced out in the larger group help to determine that the larger group should be saved. ((2005): 53)

Scanlon writes,

Since there is, we are supposing, a positive duty to save in cases in which only one person is present, this means that any nonrejectable principle must direct an agent to recognize a positive reason for saving each person. Since a second reason of this kind can balance the first - turning a situation in which one must save one into one in which it is permissible to save either of two people - the reason presented by the needs of a second person in one of these two groups must at least have the power to break this tie. ((1999): 232)

Their idea is that each interest is to be balanced against another (Kamm), or each reason is to be balanced against another (Scanlon), or each claim is to be balanced against another (Rahul Kumar, explaining Kamm and Scanlon's view in Kumar (2001)) or each person is to be balanced against another (Kamm in parts of Kamm (1993)). How you understand Kamm and Scanlon's view depends on what balancing relates: interests, reasons, something else. And how plausible these views are varies depending on what it relates. For simplicity, I follow Scanlon and assume it relates reasons. The problems I raise for the view apply if the view involves the other relata.

Kamm and Scanlon hold that, in the ABC case, the balancing of reasons supports saving Bob and Christine. It would do the same in any case like the $\mathrm{ABC}$ case. That is the lion's share of the explanation of

Must Save Many - you are required to save the many.

It isn't the whole explanation. There is the further claim that balancing is fair. Scanlon adds that no individual can complain if Must Save Many is true. Kamm adds that balancing is just - and so on. Ignore these extras and focus on balancing - it is what is common to Kamm and Scanlon's explanation. Balancing is just an image. No one thinks you put anything on scales. So, in evaluating Kamm and Scanlon's view, everything hangs on how to interpret the image. There are three possibilities:

\section{Interpretation \#1}

Maybe balancing is a decision procedure, like coin flipping or having a lottery, for figuring out who to save. To follow the decision procedure, you, the rescuer, compare the reason that favors saving Alan and the reason that favors saving Bob. Seeing they are equally strong, you put them aside and 
compare the reason that favors saving Christine to any remaining reason. There is none. So you should save Christine. When you do, you can save Bob, so you should. Some bits of Kamm and Scanlon - Kamm (1993): 117, Kamm (2005): 56, 61-62 and Scanlon (1999): 234 - seem to support this interpretation of balancing, and it is imputed to them by Wasserman and Strudler ((2003): 77, 80, 88). For the following reasons, I think it is both implausible and not the best interpretation of Kamm and Scanlon.

If balancing is a decision procedure, then unless it is just counting and noting that each stands to lose the same, then almost everyone who has ever had to choose between saving the few and saving the many has done something wrong because they have failed to deliberate permissibly. (I assume deliberating is a doing.) Doctors regularly have to save more people or save fewer. The idea that doctors actually go through a decision procedure any more sophisticated than figuring out which group of like persons is bigger is incredible.7 So if the decision procedure is more than counting and noting that each stands to lose the same, most, perhaps all, people in positions like your position in the $\mathrm{ABC}$ case act impermissibly - incredible. ${ }^{8}$

It is more charitable to interpret the decision procedure as the sort of thing people go in for, something like counting and noting each stands to lose the same. If, however, that is all there is to the decision procedure, it is not morally required just because there is no need to do either. We can build into the $\mathrm{ABC}$ case that you know you have a choice between saving one and saving two and know the costs of death are the same for each and know the costs to you of saving each are the same. To insist that you are morally required to count and note in such a case would be like insisting that, confronted with two piles of ballots, you are morally required to count them after you know how many are in each pile. Interpretation \#1 posits balancing as a rival to, say, coin flipping. But unlike coin flipping, balancing does not give everyone involved a chance, and its outcome is never in doubt. It is like a rigged ballot - you know before starting the decision procedure that it will result in a requirement to save the many. But, if so, why bother with it?

\section{Interpretation \#2}

Rather than a decision procedure, balancing can be interpreted as part of the grounds of what you are required to do. Whereas a consequentialist says the grounds for saving the many are that doing so is best, Kamm and Scanlon say the grounds, partly, are the balancing of reasons. Interpretation \#2 has it that way. Whereas, if interpretation \#1 is right, balancing is something you

\footnotetext{
${ }^{7}$ Kamm might disagree. See Kamm (1993): 139. It is unclear to me whether Kamm is saying there that interpretation \#1 is supported by the phenomenology of anyone confronted by cases like the $\mathrm{ABC}$ case, or whether she is just describing what her own phenomenology would be like.

${ }^{8}$ Scanlon would agree. He believes that, in the AB case, you are allowed to save one group rather than the other without a decision procedure ((1999): 232).
} 
do (cf. Kamm (2000): 33 and Kamm (2005): 53, 55, 62), if interpretation \#2 is right, the moral universe does the balancing.

It does so like this: In the A case, the case where only Alan's life is at stake, there is powerful reason to save Alan. In the absence of other powerful reasons, you are required to save Alan. Such other reasons are absent, so, in the A case, you are required to save Alan.

In the $\mathrm{AB}$ case, the case where only Alan and Bob's lives are at stake, there is reason to save Alan and reason to save Bob. Because the reasons are powerful, you have to save someone. Because the reasons are equally powerful - they balance - you can save either Alan or Bob.

In the $A B C$ case, interpretation \#2 says that in the presence of the fact that Christine needs saving, what, in the $\mathrm{AB}$ case, were balanced reasons to save Alan and Bob are "neutralized," in the word of Kamm and Kumar. There is, by contrast, reason to save Christine. The reason is powerful and, in the absence of other powerful reasons, you are required to save her. Such other reasons are absent - Alan and Bob's plights providing none - so, in the $\mathrm{ABC}$ case, you are required to save Christine. If you do so, you can save Bob, too. You should do so. Something like this interpretation of balancing is defended in Kumar (2001) and Suikkanen (2004), where it is attributed to Kamm and Scanlon. It is also defended in Kamm (1984), though it is walked back from in Kamm (1993): 101, 116-117. ${ }^{9}$

This interpretation makes Kamm and Scanlon's view very odd. The view is not that the reason to save Alan neutralizes the reason to save Bob in every case. If that were so, the view would have the false implication that, in the $\mathrm{AB}$ case, the case with just them - you are permitted (required?) to save no one since there is no reason to save Alan or Bob. Instead, the view is that the reason to save Alan neutralizes the reason to save Bob only in the presence of other reasons. But how could the fact that Christine needs saving and you can save her and Bob be any part of the story of why there is no reason to save Bob?

Intuitively, there are reasons to save Alan, Bob and Christine in the ABC case, but, if interpretation \#2 is true, this is incorrect. But the intuitive view leaves open how the reasons to save each person interact.

\section{Interpretation \#3}

Interpretation \#3 has the reasons work in the intuitive way: in the $\mathrm{ABC}$ case, there are reasons to save Alan, Bob and Christine. Interpretation \#3 has a story about how those reasons interact: the reasons to save Bob and Christine combine. The reason to save Alan is as powerful as the reason to save Bob - they balance. The reason to save Christine is as powerful as either. Since Bob and Christine's combine, the reason to save the many is more powerful than the reason to save Alan. So you are required to save them. This

9 "Something like" indicates that Kumar might be defending a decision procedure interpretation of balancing (see his (2001): 168). If so, the objections to interpretation \#1 apply. 
view of balancing is found in chapters five and six of Kamm (1993), Kamm (2000): 33 and Kamm (2005): 60. Otsuka attributes interpretation \#3 to Kamm and Scanlon in his (2000) and (2006), and Timmerman attributes it to them in his (2004).

How do reasons work in the following case, if interpretation \#3 is right?

Finger - You have some medicine. Without it, Fred and George will die and Helga will lose a finger. It is possible to save either Fred or George, but not both. George needs slightly less medicine than Fred. If you save George, you can use what is left of the medicine to save Helga's finger. You have no special obligations here. Death will cost Fred and George just as much. Saving lives and fingers would cost you next to nothing.

The argument from Finger against interpretation \#3 goes as follows: The reasons to save Fred and George balance. There is reason to spare Helga. If interpretation \#3 is right, it combines with - in particular, is added to ${ }^{10}$ - the reason to save George. So there is more powerful reason to save the many than the few. So, if interpretation \#3 is right, you are required to save George and Helga. This is not true. You are permitted to save Fred: if you had a choice just between George and Fred, saving Fred would clearly be permissible. So why would the fact that you can, to boot, save someone along with George from something much less serious than what threatens Fred and George show that you have to save George, can't save Fred?

Just assume you can save Fred. For the purposes of arguing against Kamm and Scanlon, there is nothing wrong with doing so - they would agree with me about the case. They are sensitive to the possibility of a counterexample like Finger. Kamm discusses such cases very sensitively and in detail and thinks her view does not have the bad consequence I think it does. She writes, "to preclude [Fred]'s chance to live in order to gain a small utility [for Helga] fails to show an adequate respect for [Fred]" (Kamm (2000): 34). And she claims that Helga has no complaint if, in Finger, there is no requirement to save the many (Kamm (2005): 62). The idea is that Fred would be wronged - because disrespected - were Helga's reason to generate a requirement, and Helga would not be wronged by that reason not generating a

${ }^{10}$ In what follows, "combines with" is always short for "is added to." This obscures something important, touched on at the end of section two: it is unclear why the reasons combine in any way and, further, unclear why their means of combination is addition.

Also, I assume that if interpretation \#3 is true, the reasons to save Bob and Christine defeat the reason to save Alan by outweighing that reason rather than by, say, undercutting it. I make the same assumption about how the reasons to save George and Helga defeat the reason to save Fred. The weight view of this case is endorsed by Scanlon in his (1999): 232, but note (1999): 397, n. 32 for some caution. 
requirement or, perhaps, she would be wronged, but less wronged. ${ }^{11}$ Kamm's claims suggest two quite different replies to the argument from Finger. First, if interpretation \#3 is correct, the reason to save Helga does not combine with the reason to save George. So there is no stronger reason to save the many than the few. Second, even if it does combine, there is no stronger reason to save the many than the few because the reason to save the few is roughly as strong as the reason to save the many, and it is rough strength that matters. I take these replies in turn.

In the ABC case, why does Christine's reason combine with Bob's? Put aside the prior question of why reasons combine at all. Assuming there is some combining, the case for adding the reason to save Christine to the reason to save Bob in this case is: deaths are things you should prevent when it is this easy and, whatever you do, Alan or Bob will die, whereas it is not true that whatever you do Christine will die. Why this makes a case for the reason to save her being added to Bob's is unclear but, clearly, if interpretation \#3 is right, it does.

The trouble is, a similar case can be made for combining the reason to save Helga with the reason to save George in Finger. If George and Fred were not in the picture, you would be required to save Helga. A soon-lost finger is not a condition - like hangnails or itches - that it is permissible to ignore when responding to it will cost you next to nothing. And whatever you do, someone will lose a life, but it is not the case that whatever you do, someone will lose a finger. Essentially, you have a choice between preventing the loss of a finger and not, where other things are equal - someone is dying either way - and saving the many is the only way to prevent it. Again, you might wonder why this shows anything about whether reasons combine, but the same worry can be pressed in the $\mathrm{ABC}$ case. My point is just that the case for combining the reason to save Christine with the reason to save Bob, whether a good case or bad, is like the case for combining the reason to save Helga with the reason to save George.

Kamm would say combining reasons in Finger is inconsistent with an "adequate respect" for Fred. If anything, thinking the reason to save Christine combines with the reason to save Bob in the ABC case, and then denying that the reason to save Helga combines with the reason to save George, is what seems a bit disrespectful. It treats Helga merely as if she were a (small!) container of disutility. But Helga is a person with something quite serious to lose if you don't help her and, furthermore, there is nothing you can do for both of the people who stand to lose more than she. This strikes me as a decent case for the reason to save her being combined with the reason to save George and, again, it strikes me as extremely similar to the case for combining the reason to save Bob with the reason to save Christine.

${ }^{11}$ Elizabeth Harman pointed out to me something slightly weird about Kamm's view here: it seems to imply that morality would wrong Fred if there were a requirement to save George and Helga. 
Kamm says that if you are not permitted to save Fred just to gain the comparatively small utility of preventing Helga from losing a finger that fails to show adequate respect for Fred. But this point can be turned against her. In Finger, think of things from Helga's point of view. If you are not required to save her, you gain... Gain what, exactly? Someone dies no matter what you do.

So if interpretation \#3 is right about how reasons work in the ABC case, I think, pace Kamm, there is a good case that the reason to save Helga combines with the reason to save George. Is there a case, stemming from Fred, against such combination? In the $\mathrm{ABC}$ case, Kamm thinks, Alan has no complaint about the combining of the reasons to save Bob and Christine. Alan is treated fairly when the reason to save him is weighed against the reason to save Bob. But then why would Fred have a complaint about combination in Finger? The reason to save him has been balanced against the reason to save George. Of course, as Kamm would point out (see Kamm (2000): 34, Kamm (2002): 480-481 and Kamm (2005): 61-63), the reason to save Helga is much less strong than the reason to save Fred. But where the reason to save Helga is less strong than the reason to save Fred, the reason to save George is not.

An appeal to the relative size of Helga and Fred's losses seems unhelpful. The situation seems like this to me: there are cases, like the ABC case, where prima facie we ought save the many. There are cases, like Finger, where prima facie we can but need not. And there are cases in between - cases where we can save one from death or another from death plus save a third from something less bad than death but worse than losing a finger. We can, for example, save one from death or another from death while saving a third from losing his legs. Again, prima facie we ought to save the many. An appeal to what is lost - a life, a finger, legs - explains that the losses in the first and third case give you more reason to save the many than the few; the losses in the second do not. There is something to this. But, ultimately, I think it is unsatisfying without an answer to the following questions: how big a loss is big enough? And why?

I worry that what is going on with an appeal to the "size" of a loss is just that we count a loss as "big enough" if we antecedently judge that we ought to save the many. We have no grip on what a big enough loss is apart from one the presence of which brings about a requirement to save the many. You might try to get a grip by appealing to whether the loss is morally important or whether someone would have a complaint if her loss is not big enough or someone else would be disrespected if it is. But I have argued that those tests don't give the intuitive results in Finger.

So the first way out of the argument from Finger is a no-go. The case to combine the reason to save Helga with the reason to save George in Finger is like the case to combine the reason to save Christine with the reason to save Bob in the ABC case. That the reason to save Helga is less strong than the other reasons is irrelevant to whether it combines. But perhaps it is relevant 
in another way. Kamm might argue that the reason to save the many in Finger is only slightly stronger than the reason to save the few. The reason to save the many in the $\mathrm{ABC}$ case, by contrast, is much stronger than the reason to save the few. So perhaps what is wrong with the objection from Finger is the inference from the reason to save Helga combining with the reason to save George to there being stronger reason to save them. No doubt, there is slightly stronger reason. But the reasons are roughly as strong. And it is rough strength that matters.

I think Finger can be modified in such a way to still raise a problem for interpretation \#3; a case can be constructed where, if the reasons work as interpretation \#3 says, then you have much stronger reason, roughly speaking, to save the many than the few but, still, you need not. But judgments about cases like that are controversial, and defending them takes a great deal. There are two more apparent problems with the appeal to rough strength.

First, what drives these judgments of rough strength? On the one hand, it seems obvious that the reason to save Bob and Christine is stronger, roughly speaking, than the reason to save Alan. And it seems, though maybe this is not obvious, that the reason to save Fred is just as strong, roughly speaking, as the reason to save George and Helga. And it seems obvious that were Helga to lose her legs in Finger rather than lose a finger, the reason to save her and George would be stronger, roughly speaking, than the reason to save Fred. But I worry that what drives these judgments is that it seems obvious that you ought to save Bob and Christine, ought to save George and Helga if Helga will lose her legs, and need not save George and Helga if Helga will only lose a finger. If so, the appeal to rough strength is not part of the story of why you have to save the many. It is more like a post hoc rationalization of what we already believe to be the case than an explanation of it. Interpretation \#3 promised to be that explanation.

Second, even if we think an appeal to rough strength is illuminating, without a story of what makes for roughly stronger reasons, interpretation \#3 is problematic. Taurek's view can be thought of as insisting that the reason to save Alan is roughly as strong as the reason to save any number of persons. Appealing to rough strength and then insisting that the reason to save Bob and Christine is roughly stronger than the reason to save Alan just begs the question against Taurek. What needs defending is a story about why, in the $\mathrm{ABC}$ case, the reason to save the many is stronger, roughly speaking, than the reason to save the few, whereas, in Finger, the reason to save the many is no stronger, roughly speaking, than the reason to save the few. There are two ways to develop Taurek's challenge: one asks for why reasons combine at all in the $\mathrm{ABC}$ case; the other concedes that they do, then insists that the combined reason to save Bob and Christine is only roughly as strong as the reason to save Alan.

What we wanted was an explanation of why you ought to save the many. What interpretation \#3 now seems to offer is an explanation that assumes that reasons combine in a certain way and assumes that, if they do, the reason 
to save Bob and Christine is stronger than the reason to save Alan. Without defense of these assumptions, I worry this isn't really an explanation so much as a promise one can be given. Can it?

There is some reason to think not. Taurek (1977) defends

Can Save Few - you are required to save someone but permitted to save the many or the few.

A natural way of defending that view - not Taurek's own - is to claim, first, that in the $\mathrm{ABC}$ case, there are reasons to save Alan, Bob and Christine. So interpretation \#2 is wrong. Second, the reasons to save Bob and Christine do not combine. So interpretation \#3 is wrong. This way of defending Taurek commits to there being no more powerful reason to save Bob and Christine than to save Alan. There are more reasons. And these reasons are powerful: you have to save someone. But the reason to save Alan is as powerful as any number of like reasons. So, in the $\mathrm{ABC}$ case, you have to save someone, and you can save Alan, or Bob and Christine.

Outlining his view of how reasons work in the ABC case, Scanlon writes, "Since there is... a positive duty to save in cases in which only one person is present,... any nonrejectable principle must direct an agent to recognize a positive reason for saving each person. Since a second reason of this kind can balance the first...the reason presented by the needs of a second person in one of these two groups must at least have the power to break this tie" ((1999): 232; my italics). By the italicized bit, Scanlon means the reason to save the second person must generate a requirement to save the many. Why "must"? Why couldn't reasons work in the Taurekian way? Kamm and Scanlon think this is ruled out since, if they worked in the Taurekian way that would lead to Can Save Few and that view, they think, is unfair, and no unfair view is true. Section 1 of this paper is important here: Can Save Few is fair, by Kamm and Scanlon's lights. So why think reasons can't work Taurek's way and, indeed, must work the way interpretation \#3 recommends?

Much more would need to be said to defend the Taurekian idea - is it even an idea? An outline of an idea? - but it has this much going for it. Kamm, Scanlon and the Taurekian are debating how reasons work in the $\mathrm{ABC}$ case. So put that case aside. When you look at a case like Finger, this is some support for the Taurekian, some reason to doubt interpretation \#3. Unlike interpretation \#3, the Taurekian account of how reasons work in the $\mathrm{ABC}$ case can be easily adapted to handle Finger. If it is right, it is permissible to save Fred or to save George and Helga, but you are required to save someone.

Furthermore, since Kamm and Scanlon reject that reasons combine in Finger, and accept they combine in the $\mathrm{ABC}$ case, they have to explain why there is combination just in certain cases. Why not in all cases? Or none? And what, exactly, would Christine's complaint be in the ABC case if there were no combining of reasons? 
There is not just a problem for Kamm and Scanlon here. Interpretation \#3 is the most obvious view of how reasons work in the ABC case and it is it - not Scanlon's contractualism or the claim that no unfair view is true or... that has a problem distinguishing the $\mathrm{ABC}$ case from Finger. Anyone who accepts the view of how reasons work, plus Kamm and Scanlon's (and my) judgment about what is permissible in Finger, has this problem. Taurek's solution - Can Save Few - seems totally bizarre, but it grows out of a natural view of how reasons work in Finger. In response, you might, as Bradley (2009) does, reject the judgment about what is permissible in Finger. This is barely less bizarre to me than Can Save Few. If the cost of Must Save Many is a requirement to save the many in Finger, this detracts a great deal from the intuitive plausibility of the position. Must Save Many, just like Can Save Few, would be unintuitive.

\section{Conclusion}

I have argued that Kamm and Scanlon's argument against Can Save Few does not work because, by Kamm and Scanlon's own lights, Can Save Few is fair. ${ }^{12}$ I have argued that Kamm and Scanlon's argument for Must Save Many, interpreted in any of the three ways distinguished above, does not work.

Taurek has two main arguments for Can Save Few. The better argument, I think, is that there is a plausible explanation of it and no plausible way of explaining its only real rival, Must Save Many: it is not better to save the many, he thinks; it is not required by fairness (the rejection of Kamm and Scanlon's argument against Can Save Few supports Taurek here); it is not required by some special obligation; and, saving the few violates no rights. Taurek's defense of the claim that there is no explaining Must Save Many is not convincing: he considers just four putative explanations and not Kamm and Scanlon's. If I am right that their explanation is not compelling, this strengthens Taurek's case that there is no explaining Must Save Many.

As to whether Can Save Few is true, I think it is, though I have not argued that here. ${ }^{13}$ The problems for Kamm and Scanlon's explanation of Must Save Many generalize to other nonconsequentialist explanations. So there is no explaining Must Save Many, or the explanation is consequentialist, or Can Save Few is true. Cases like Finger, I think, show that the last is correct.

Tyler Doggett

University of Vermont

Philosophy Department

tdoggett@uvm.edu

12 Is Can Save Few fair by other lights? Broome's account of fairness has only Can Save Few supplemented with the claim that you are required to give each an equal chance at survival as fair. Plain Can Save Few is not fair, Broome thinks, and neither is Must Save Many. See Broome (1990) and (1998).

13 I do in "Saving the Few" (ms.). 


\section{References}

Anscombe, G.E.M. 1967. "Who is Wronged?," Oxford Review 5: 16-17.

Bradley, Ben. 2009. "Saving Lives and Flipping Coins," Journal of Ethics and Social Philosophy 3.

Brock, Dan. 1998. "Aggregating Costs and Benefits," Philosophy and Phenomenological Research 58: 963-967.

Broome, John. 1990. "Fairness," Proceedings of the Aristotelian Society 91: 87-102.

Broome, John. 1998. "Kamm on Fairness," Philosophy and Phenomenological Research 58: 955961.

Hsieh, Nien-hê, Alan Strudler and David Wasserman. 2006. “The Numbers Problem,” Philosophy and Public Affairs 34: 352-372.

Kamm, Frances Myrna. 1984. "Equal Treatment and Equal Chances," Philosophy and Public Affairs 14: 177-194.

Kamm, Frances Myrna. 1993. Morality, Mortality, Volume One. New York: Oxford University Press.

Kamm, Frances Myrna. 1998. "Précis," Philosophy and Phenomenological Research 58: 939-945.

Kamm, Frances Myrna. 2000. "Nonconsequentialism” in Lafollette, Hugh, ed., The Blackwell Guide to Ethical Theory. Malden, MA: Blackwell. Reprinted in Kamm (2007). Page numbers refer to the reprint.

Kamm, Frances Myrna. 2002. “Owing, Justifying, and Rejecting," Mind 111: 323-354. Reprinted in Kamm (2007). Page numbers refer to the reprint.

Kamm, Frances Myrna. 2005. “Aggregation and Two Moral Methods," Utilitas 17: 1-23. Reprinted in Kamm (2007). Page numbers refer to the reprint.

Kamm, Frances Myrna. 2007. Intricate Ethics. New York: Oxford University Press.

Kumar, Rahul. 2001. "Contractualism on Saving the Many," Analysis 61: 165-170.

Lübbe, Weyma. 2008. "Taurek's No Worse Claim,” Philosophy and Public Affairs 36: 69-85.

Munoz-Dardé, Véronique. "The Distribution of Numbers and the Comprehensiveness of Reasons," Proceedings of the Aristotelian Society 105: 207-233.

Norcross, Alastair. 2002. "Contractualism and Aggregation," Social Theory and Practice 28: 303314.

Otsuka, Michael. 2000. "Scanlon and the Claims of the Many Versus the One," Analysis 60: 288-293.

Otsuka, Michael. 2006. "Saving Lives, Moral Theory, and the Claims of Individuals," Philosophy and Public Affairs 34: 109-135.

Parfit, Derek. 2003. "Justifiability to Each Person," Ratio 16: 368-390.

Raz, Joseph. 2003. "Numbers, With and Without Contractualism," Ratio 16: 346-367.

Scanlon, T.M. 1999. What We Owe to Each Other. Cambridge, MA: Harvard University Press.

Suikkanen, Jussi. 2004. "What We Owe to the Many," Social Theory and Practice 30: 485-506.

Taurek, John. 1977. "Should the Numbers Count?," Philosophy and Public Affairs 6: 293-316.

Timmerman, Jens. 2004. "The Individualist Lottery: How People Count, but not Their Numbers," Analysis 64: 106-112.

Wasserman, David and Strudler, Alan. 2003. "Can a Nonconsequentialist Count Lives?," Philosophy and Public Affairs 31: 71-94. 